\title{
TECNOLOGIA PAUL WURTH DE REFORMA A QUENTE EM COQUERIAS*
}

Helênio Resende Silva Junior ${ }^{1}$ Antonio Esposito 2 Francesco Valdevies ${ }^{3}$

\section{Resumo}

Em coquerias, o período compreendido entre o início de operação até a desativação devido final de vida útil é relativamente longo. Torna-se tarefa muito difícil determinar-se o tempo exato de desativação por degradação uma vez que as coquerias possuem muitos fornos tipo batelada e o grau individual de degradação varia de acordo com as condições operacionais e método de preservação aplicados. Apesar dos cuidados adotados na operação e manutenção das coquerias, torna-se inevitável um desgaste inexorável em suas estruturas com o passar dos anos, com progressivo decréscimo na capacidade eficaz de produção até a sua paralisação. Tendo em vista o elevado custo envolvido na construção de novas coquerias, tornase prioridade para as siderúrgicas prolongarem ao máximo a vida útil das baterias existentes, adotando o tipo de reparo adequado a cada fase da vida da bateria. $\mathrm{O}$ presente trabalho tem o objetivo de descrever os tipos de reparo em baterias de coque disponíveis, visando restaurar as estruturas e recuperar a capacidade produtiva das coquerias, respeitando as normas ambientais vigentes.

Palavras-chave: Coqueria; Reforma a quente; Reparo.

\section{PAUL WURTH TECHNOLOGY FOR COKE OVEN HOT REPAIR Abstract}

In Coke Ovens, the period from the battery start-up due end of life time is relatively long. It becomes very difficult to determine the exact time for deactivation by degradation since the coke ovens have many batch type ovens and its individual degradation degree varies according to operating and maintenance methods used. Despite the care adopted in the operation and maintenance of coke ovens, it's inevitable an inexorable wear in their structures over the years, with progressive decrease in its effective production capacity until its shutdown. Considering the costs involved in building new coke oven units, becomes a priority for steel companies to extend the most of batteries useful life, promoting the appropriate type of repair for each phase of a battery operating life. This paper aims to describe the available types of repair in coke ovens batteries, aiming to restore the batteries' structures and its productive capacity, respecting the existing environmental standards.

Keywords: Coke oven batteries; Hot repair, Reform.

Ing. MBA, Marketing Vendas, Tecnologia Coqueria, Paul Wurth Brasil, Belo Horizonte, MG, Brasil. Ing., Head of Coke Oven Machines dept., Paul Wurth Italia S.p.a. , Genoa, Italy

Ing. Coke Oven Hot Repair Technology, Expert Consultant Advisor, Taranto, Italy. 


\section{INTRODUÇÃO}

A Coqueria tem como finalidade básica a produção de coque metalúrgico para consumo nos Altos fornos. Para o consumidor clássico de coque nas usinas integradas - o Alto Forno - o coque produzido em baterias de fornos de coque satisfaz adequadamente as exigências de qualidade, bem como atende ao balanço energético global da usina de forma otimizada.

Apesar de sua relevância no contexto da siderurgia integrada a coque, nos últimos anos, a sobrevivência da coqueria vem sendo questionada devido principalmente aos impactos ambientais e aos custos de instalações e produção (Capex e Opex).

Apesar das pressões externas, a Coqueria ainda não tem um substituto do seu porte que atenda a todos os requisitos, ao mesmo tempo em que os processos alternativos estão ainda em fase de indefinição quanto à viabilidade técnicoeconômica. A coqueria continuará sendo, ao que tudo indica, o processo mais viável para obtenção de coque nas próximas décadas.

\section{VIDA ÚTIL DE UMA BATERIA DE FORNOS DE COQUE}

O quadro global de coquerias no mundo mostra que além das crescentes exigências de meio ambiente e de saúde ocupacional, uma grande parcela das atuais coquerias em operação no mundo são unidades antigas, muitas em final de vida útil e com significativos impactos ambientais. Essas coquerias estão sob forte pressão ambiental e trabalhista para se manterem em operação.

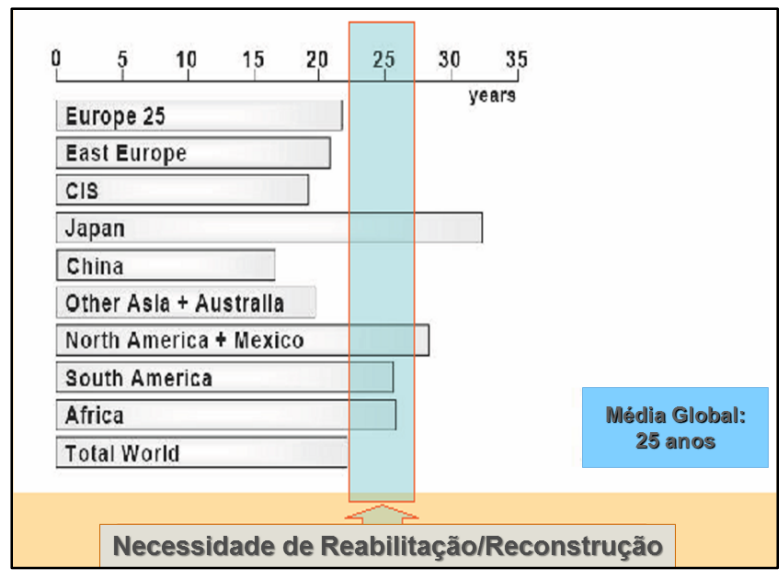

Figura 1 - Idade média global das coquerias e necessidade de reparo (fonte: Resource-Net)

A grosso modo, admite-se que a vida útil das baterias de coque pode ser avaliada como se segue:

- Vida útil inferior a 20 anos :

má performance

- Vida útil entre 20 e 30 anos :

performance adequada

- Vida útil superior que 30 anos: boa performance, porém requer cuidados especiais nessa fase.

Analisando-se outro parâmetro, a referência mundial mostra que a execução de reformas de grande porte ou mesmo a desativação de coquerias ocorre quando uma bateria atinge uma média entre 10.000 a 15.000 desenfornamentos por forno individual. 


\section{DETERIORAÇÃO DAS ESTRUTURAS DE UMA BATERIA DE COQUE}

As baterias de coque são equipamentos constituídos pelo empilhamento de tijolos de sílica, sílico-aluminosos e isolantes amarrados transversalmente e longitudinalmente por tirantes metálicos que garantem sua estabilidade operacional. As baterias de fornos de coque, após muitos anos em operação contínua, apresentam desgastes inevitáveis em suas estruturas metálicas e refratárias.

Ao longo do tempo em operação contínua, a estrutura refratária dos fornos sofre danificações tais como trincas, escamamentos, desgastes por abrasão, choques térmicos, impacto, perda juntas entre tijolos, devido, entre outros fatores, aos sucessivos choques térmicos e permanente stress termomecânico gerados nos ciclos sequenciais e ininterruptos de coqueificação. As regiões dos fornos próximas às portas são as mais afetadas devido aos choques térmicos mais intensos pela abertura das portas dos fornos a cada ciclo operacional.

Defeitos superficiais nos refratários provocam a perda da planicidade requerida na superfície das paredes e soleiras, gerando engaiolamentos de carga. A deterioração das estruturas e condutos refratários do sistema de aquecimento compromete toda a performance térmica das baterias.

Pelas trincas passantes nas paredes passa a ocorrer indevida comunicação dos fornos com as câmaras de combustão com passagem de gás cru vindo do forno que afeta a estequiometria da combustão e provoca emissões poluentes. Essas emissões são a visível e questionável "fumaça preta" nas chaminés das baterias.

Em paralelo, existe uma tendência de afrouxamento e afastamento das estruturas metálicas responsáveis pela contenção e amarração do conjunto refratário formado principalmente pelos fornos, câmaras de combustão, regeneradores e topo. As diferenças nos coeficientes de dilatação dos materiais refratários e metálicos também contribuem para essas distorções, agravando o quadro de deficiência na sustentação, contenção e estanqueidade entre as estruturas.

As anomalias descritas evoluem em gravidade e enfraquecem progressivamente a estrutura dos fornos, comprometendo sua coesão, robustez e eficiência.

\subsection{Mecanismo Simplificado de Avanço da Degradação da Alvenaria Refratária}

Podemos assumir que o mecanismo de degradação de uma bateria seria o seguinte:

- Degradação dos tijolos refratários:

- Trincas na matriz refratária devido a choques térmicos;

- Lascamentos, fendas e perda de massa por stress termomecânico;

- Desgastes induzidos nos refratários por ações externas (acidentes).

- Queda nas juntas entre tijolos e desprendimento de argamassa de reparo.

- Afrouxamento do sistema de amarração da bateria devido a:

- Projeto original ineficiente do sistema de escoramento (bracing);

- Regulagem inadequada do sistema de escoramento - tirantes e molas;

- Quebras e rupturas em tirantes e perda de eficiência das molas;

- Acidentes operacionais.

- Expansão anormal dos fornos:

- Expansão indevida da alvenaria refratária das paredes dos fornos;

- Expansão na região do topo - abertura da parte superior da bateria;

- Queda de tijolos e perda de matriz;

- Afastamento entre a contensão metálica e os refratários dos fornos. 


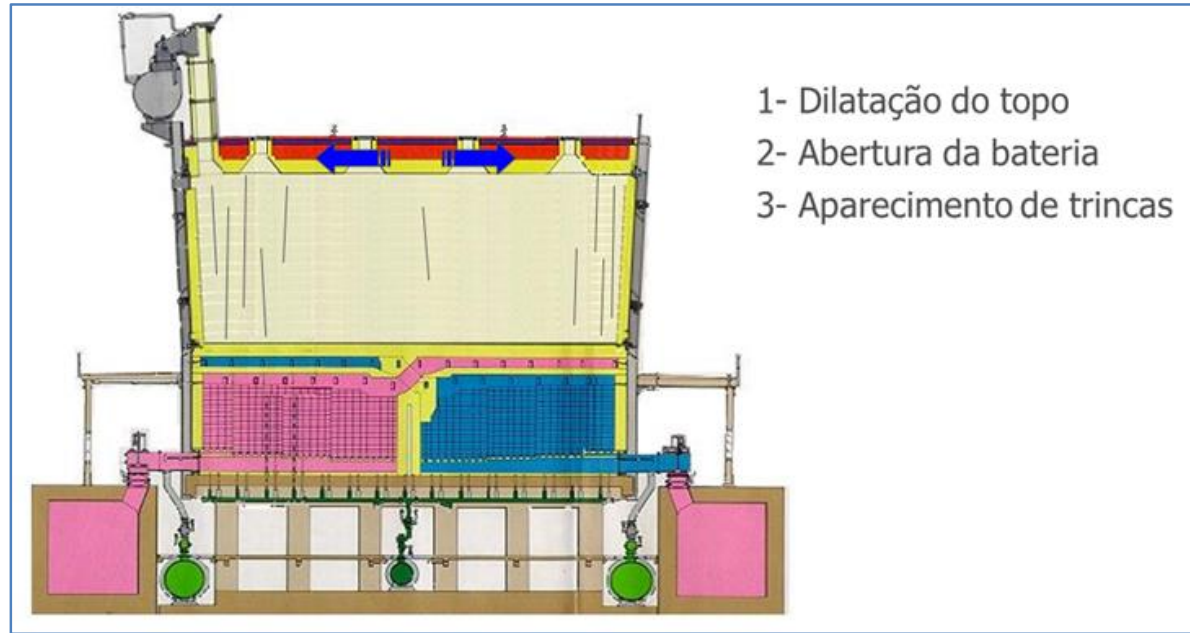

Figura 2 - Tendência de degradação de uma bateria (fonte: Costa, L.C. Usiminas Cosipa)

- Degradação sistema de aquecimento e em regeneradores:

- Má combustão nas câmaras de combustão:

- Controle térmico inadequado - estequiometria de combustão;

- Vazamento de gás cru do forno para as câmaras;

- Colapso nos regeneradores (curto circuito ar/gás sob as câmaras)

- Drástica redução de temperatura em câmaras extremas;

- Danificação permanente de refratários sílica/sílico aluminoso/checkers

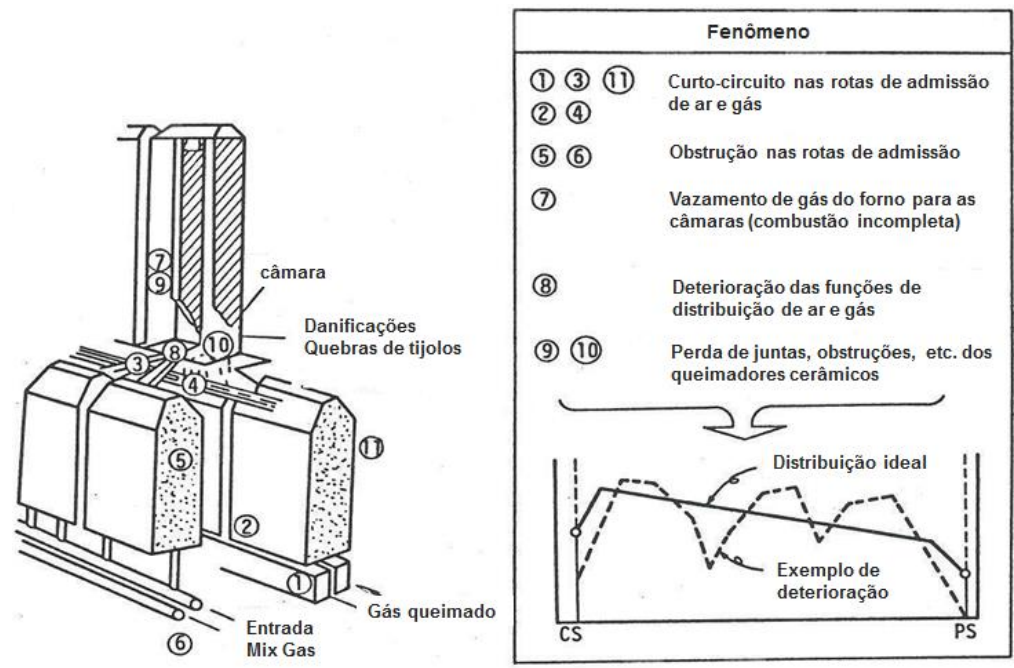

Figura 3 - Deterioração do sistema de aquecimento (fonte: Nippon Steel)

A vida útil de uma bateria depende diretamente das forças e momentos atuantes nas paredes dos fornos. As principais cargas que levam stress à estrutura são:

- Pressão de coqueificação (swelling pressure);

- Forças do empurramento do coque;

Peso e forças horizontais induzidas pelo Carro de Carregamento.

Podemos considerar que em geral as baterias percorrem o ciclo abaixo no decorrer de sua vida útil operacional: 


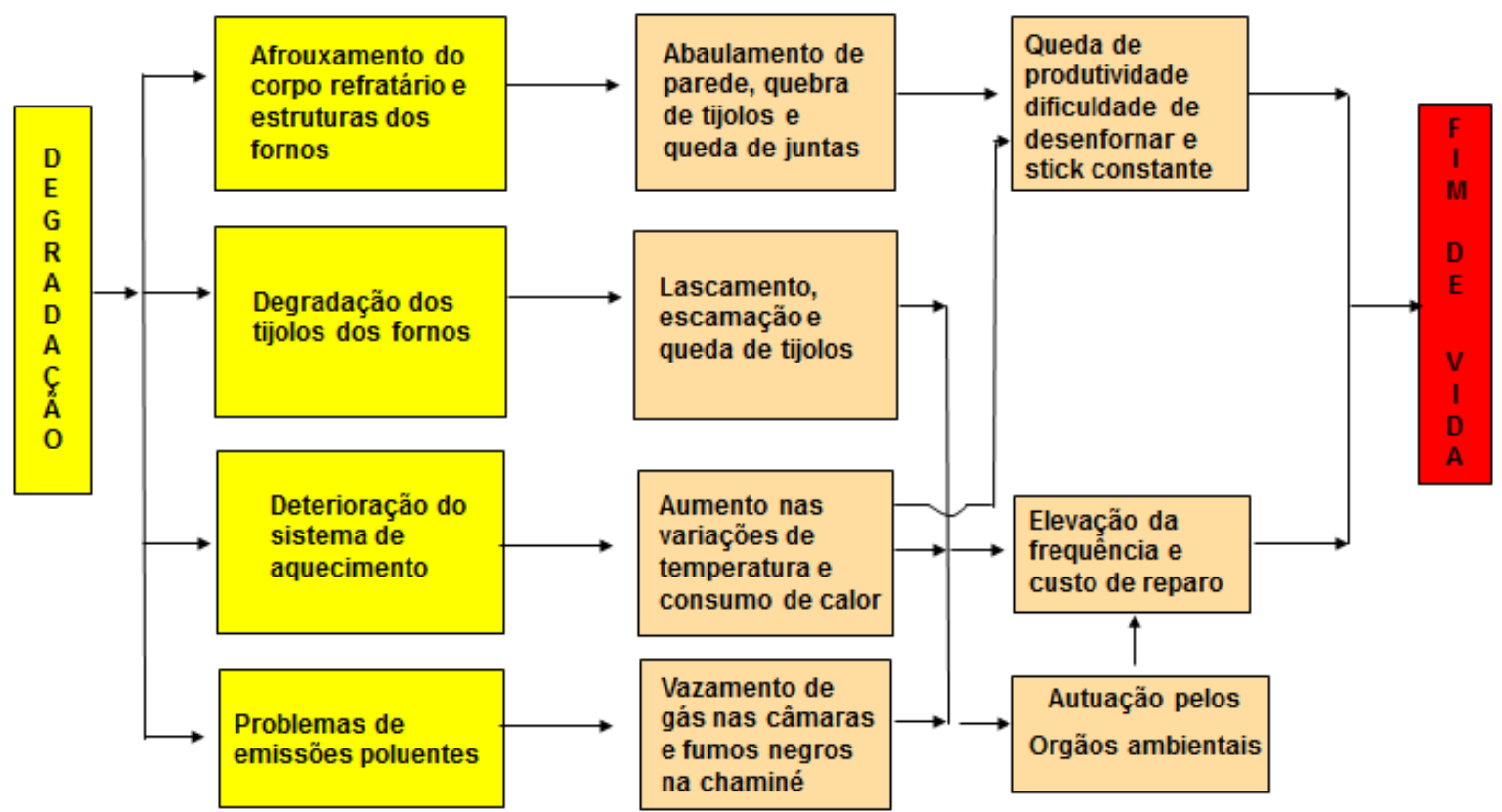

Figura 4 - Mecanismo de degradação das baterias (fonte: Costa, L.C Usiminas Cosipa).

\subsection{Métodos de Reparos Paliativos}

A conservação e preservação das estruturas refratárias e metálicas das baterias dependerão diretamente das metodologias de Controle Operacional, Controle Térmico e Preservação aplicados pelas empresas que assegurem a prática de padrões de operação compatíveis com a idade e desgaste das baterias.

Como exemplo, citamos os métodos de reparo temporário ou paliativo existentes que consistem na aplicação de massa refratária sobre as trincas e fendas dos fornos, recompondo e recuperando temporariamente a estanqueidade das paredes.

Esses métodos somente são eficientes enquanto a matriz do tijolo que irá receber a massa estiver em boas condições de resistência. Após muitos anos em operação continua, existem muitas regiões dos fornos nas quais essa matriz está comprometida, notadamente próximo às portas dos fornos.

Aliado a esses métodos, as empresas desenvolvem todo um planejamento de preservação e reparo das baterias visando prolongar sua vida útil operacional. $\mathrm{O}$ objetivo desse conjunto de ações é obter o prolongamento máximo da vida útil das baterias.

Ressalta-se que em todas as atividades e medidas preventivas e corretivas comentadas, as empresas devem zelar em manter equipes capacitadas e comprometidas com a execução das medidas necessárias, sendo o fator humano preponderante no sucesso almejado.

No esquema abaixo se pode estimar os impactos nos prolongamento da vida útil das baterias pela correta aplicação dos métodos de reparos a adequados a cada idade: 


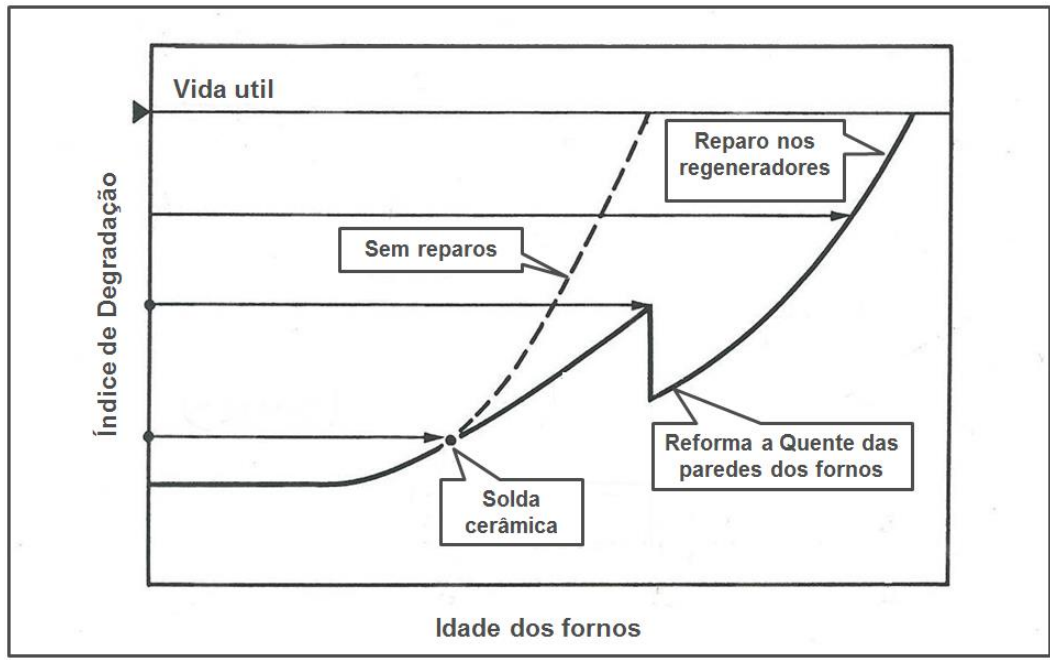

Figura 5 - Vida útil e efeitos esperados em manutenções de fornos (fonte: Nippon Steel)

\section{PLANO DE RECUPERAÇÃO DE BATERIAS:}

Apesar de todos os cuidados e medidas preventivas adotadas torna-se inevitável que as coquerias ao se aproximarem do final de vida útil demonstrem evidentes sinais de desgaste. Nessa fase, há a exigência de maior gasto em preservação e manutenções das estruturas, enquanto ocorre um progressivo decréscimo na capacidade de produção até a sua paralisação. Estes impactos devem constar do planejamento de longo prazo das empresas.

Recomenda-se estabelecimento de um Plano de Recuperação das Baterias, que contempla as seguintes fases:

Fase 1 - Diagnose da Bateria

Fase 2 - Plano de Preservação até a Reforma

Fase 3 - Reforma da Bateria

\subsection{Diagnose das Baterias}

A diagnose das baterias visa avaliar as condições das funções básicas das baterias:

\begin{tabular}{|l|l|l|}
\hline Item de diagnose & Objetivo & $\begin{array}{l}\text { Verificar a adequação da distribuição de } \\
\text { temperaturas para atender à produção. } \\
\text { câmaras de combustão }\end{array}$ \\
\hline $\begin{array}{l}\text { Sistema de escoramento - } \\
\text { Dilatação da alvenaria refratária }\end{array}$ & $\begin{array}{l}\text { Verificar a eficiência do sistema de } \\
\text { escoramento das baterias através do grau e } \\
\text { expansão das estruturas da bateria } \\
\text { (afrouxamento da amarração) }\end{array}$ & $\begin{array}{l}\text { Verificar a estanqueidade dos fornos, a partir } \\
\text { dos vazamentos. }\end{array}$ \\
\hline $\begin{array}{l}\text { Vazamento de gás dos fornos para } \\
\text { as câmaras }\end{array}$ & $\begin{array}{l}\text { Verificar a magnitude das danificações nos } \\
\text { tijolos }\end{array}$ \\
\hline $\begin{array}{l}\text { Danificação dos tijolos das paredes } \\
\text { dos fornos }\end{array}$ & \\
\hline
\end{tabular}


A partir da correta avaliação das informações obtidas na diagnose, aliada a uma criteriosa verificação dos dados operacionais, históricos dos fornos e métodos de preservação e reparos praticados, pode-se traçar um plano de recuperação das baterias e os métodos de reformas definitivos a serem adotados.

\subsection{Plano de Preservação da Bateria até a Reforma}

É o conjunto de contramedidas a serem implantadas visando conter o avanço da degradação e manter as baterias estabilizadas até a viabilização dos reparos definitivos.

Objetivos:

- Conter avanço da degradação nas estruturas refratárias e metálicas;

- Evitar aumento de escopo da reforma;

- Evitar colapso e paralisação da bateria.

Devem ser atacados pontos críticos em caráter emergencial:

- Vazamentos de gás nas câmaras de combustão;

- Combater a ocorrência de chamas entre as estruturas de amarração;

- Troca emergencial de componentes: tijolos, metálicos, etc;

- Intensificar a projeção de massa e solda cerâmica;

- Substituição de tijolos, dentre outros.

Nessa fase deverão ser corretamente definidos os recursos humanos e de materiais necessários para execução do plano, e a alocação dos recursos necessários.

\subsection{Reforma a Quente : Tipos de Reparo em Baterias de Coque}

A solução para a recuperação definitiva e eficaz de danificações avançadas e irreversíveis nas estruturas dos fornos de uma bateria de coque é a execução de uma reforma de grande porte nas baterias, que consiste basicamente na demolição e reconstrução parcial ou total das paredes de aquecimento.

A definição do momento de uma intervenção desse porte decorre da diagnose dos fornos, levando em conta o estado de degradação, os custos e ineficácia dos reparos paliativos. A partir de determinado estágio, o avanço da deterioração dos fornos torna-se superior à capacidade de executar reparos paliativos. $\mathrm{O}$ aumento do número de fornos paralisados para reparo gera significativas perdas de produção.

Nessa fase, a danificação dos fornos cresce em progressão geométrica, enquanto a capacidade de reparos caminha em progressão aritmética. Nesse ponto da vida da bateria não se consegue manter os índices de operação e torna-se recomendável a realização imediata de reforma a quente, ao invés de se prosseguir executando sucessivos reparos temporários de eficácia reduzida e de custo crescente.

Temos a seguir um resumo das principais opções para recuperação de baterias 


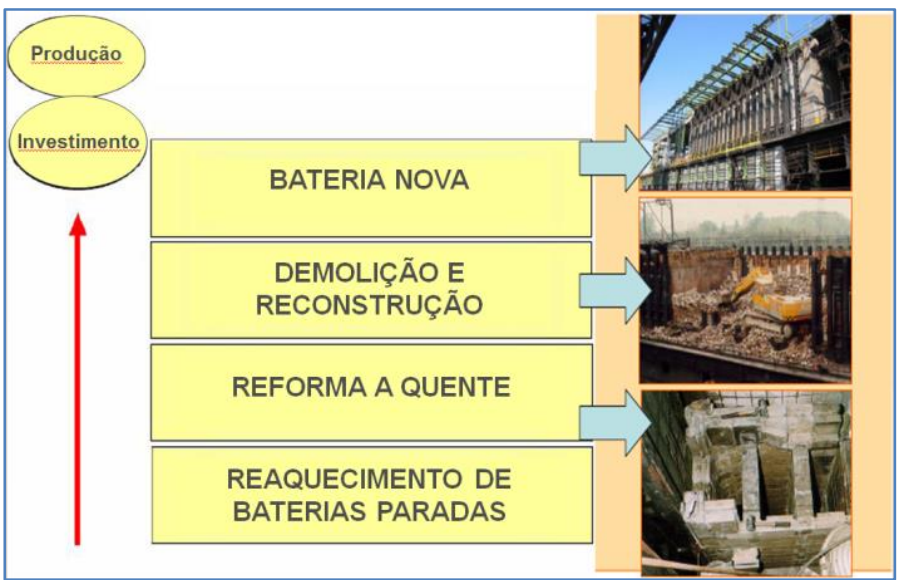

Figura 6 - Opções de recuperação de baterias de coque (Paul Wurth)

\section{REFORMA A QUENTE EM FORNOS DE BATERIAS DE COQUE}

O conceito de reforma a quente em baterias consiste na substituição apenas das partes danificadas e reaproveitamento das partes consideradas em boas condições. Essa reforma leva em consideração que apenas parte das estruturas está danificada e que nesse caso não se justifica o completo descarte da bateria.

Em linhas gerais são substituídas as partes danificadas das paredes, as estruturas metálicas de amarração e demais estruturas acessórias correspondentes às áreas de abrangência do reparo.

O esquema abaixo mostra um escopo clássico desse tipo de reforma:

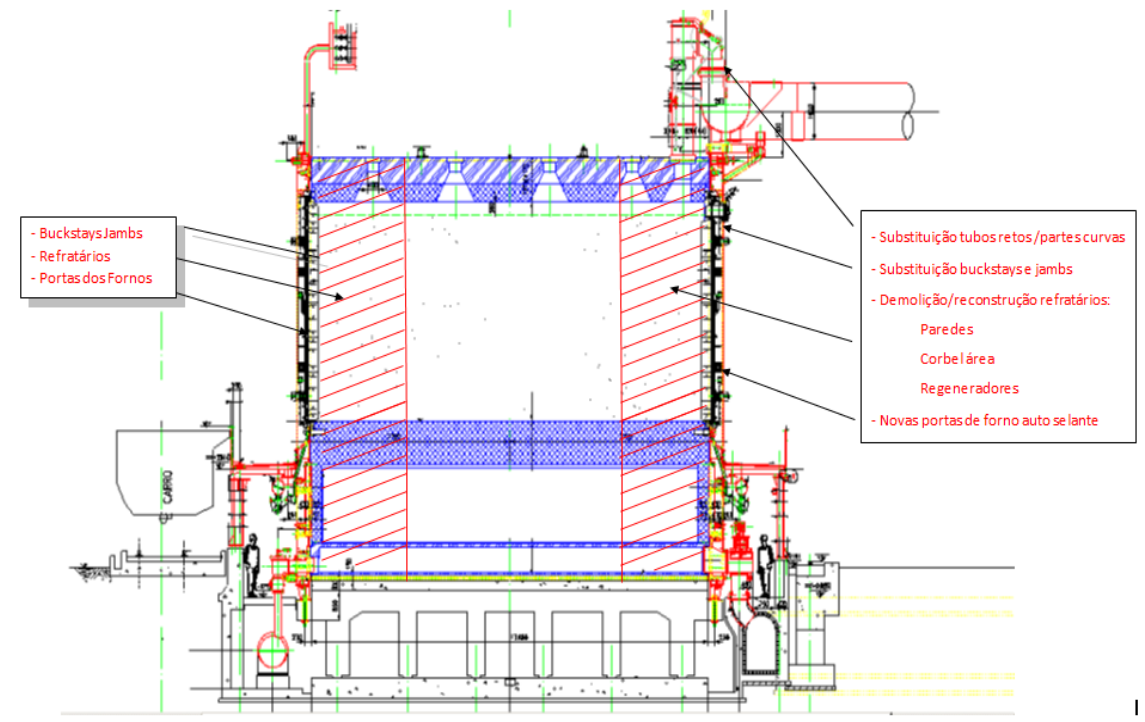

Figura 7 - Escopo básico de partes substituídas em uma reforma a quente de bateria (Paul Wurth)

Basicamente seleciona-se o grupo de câmaras a ser reparadas, promove-se o correto resfriamento, isolamento, demolição e remoção das partes danificadas.

Em seguida, executa-se a reconstrução das novas câmaras de combustão, respeitando-se rigorosamente as dimensões e projeto originais, havendo uma perfeita concordância entre as partes substituídas e partes remanescentes.

Forma-se uma junta de união entre as partes novas e remanescentes, que na metodologia aplicada pela Paul Wurth dispensa o uso de solda cerâmica para vedação e junção, o que reduz significativamente os custos do reparo. 


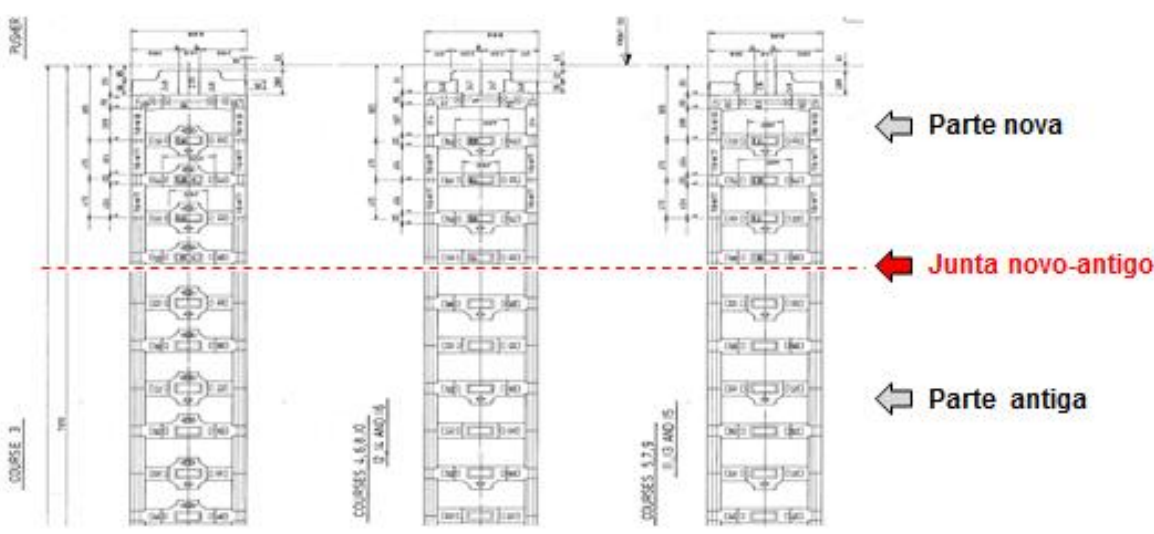

Figura 8 - Esquema de substituição parcial de câmaras de combustão das paredes dos fornos

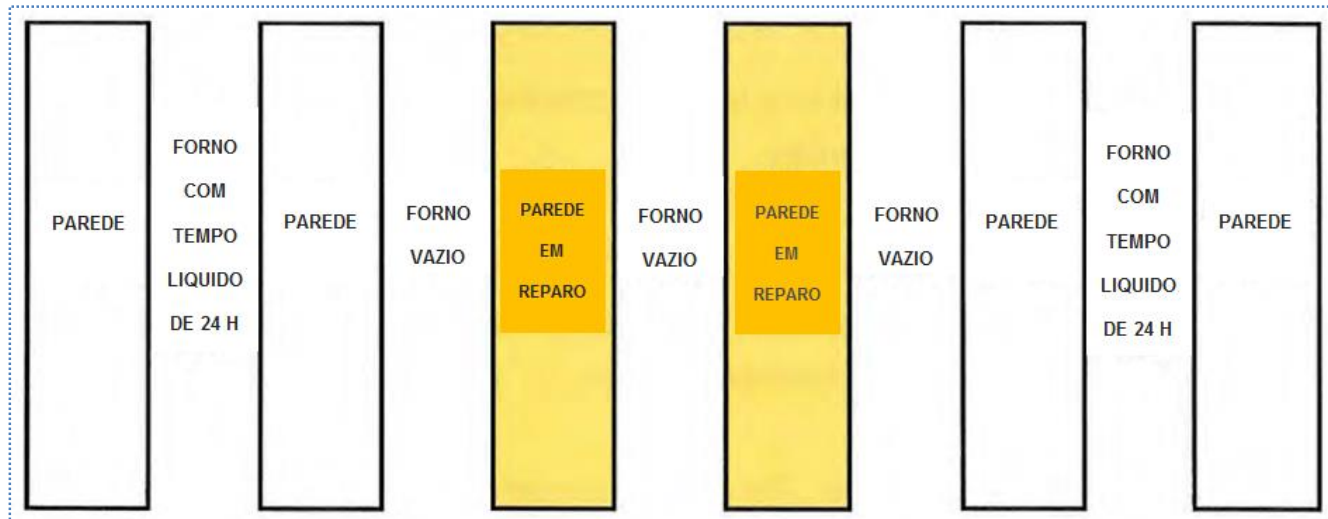

Figura 9 - Esquema de fornos para reparo

A reforma é realizada em grupos paredes, sendo realizados reparos em blocos sequenciais até que todos os fornos tenham sido reparados.

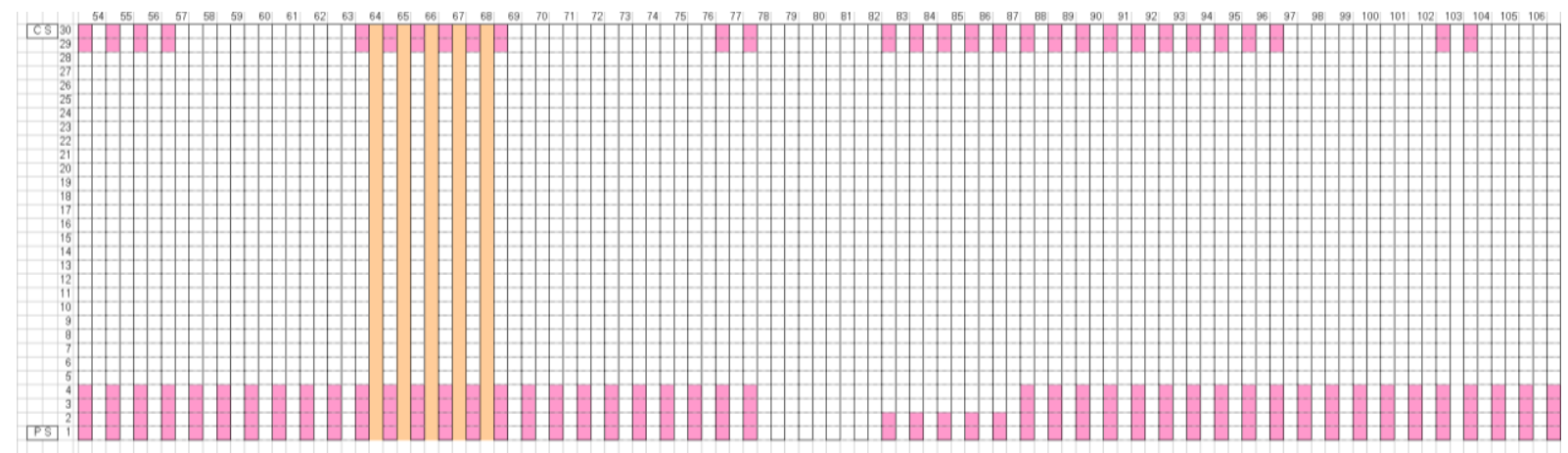

Figura 10 - Divisão das paredes em blocos de reparo (Paul Wurth).

A seguir descrevemos as etapas básicas da reforma a quente de câmaras extremas: 


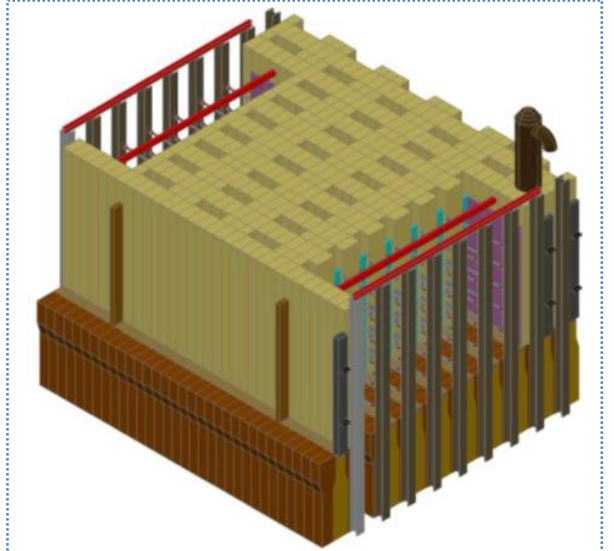

Figura 11 - Regiões danificadas demolidas

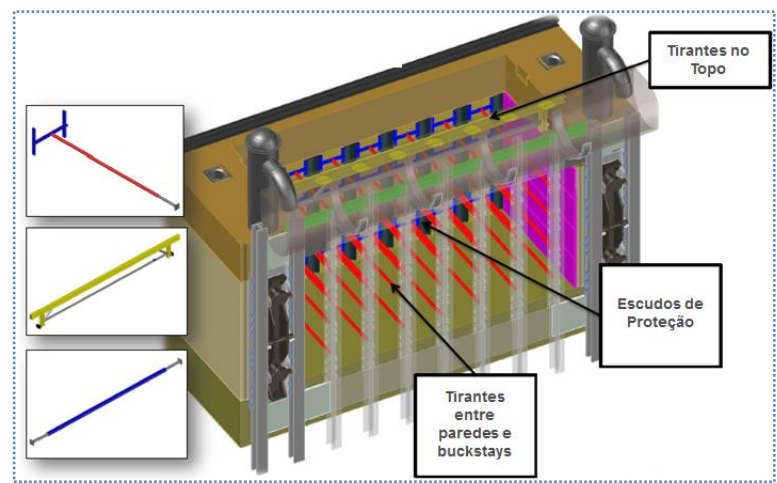

Figura 13 - Demolição e instalação dos tirantes

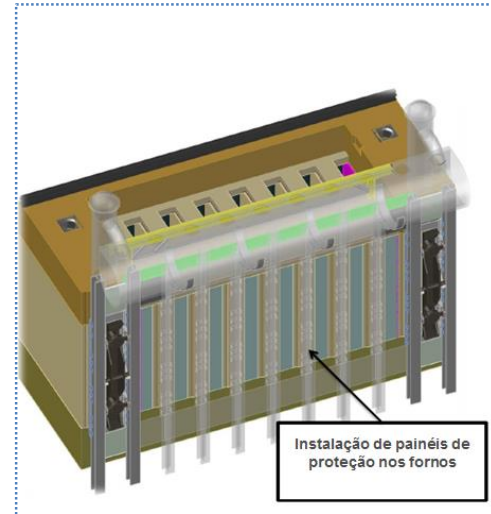

Figura 15 - Reaquecimento dos fornos

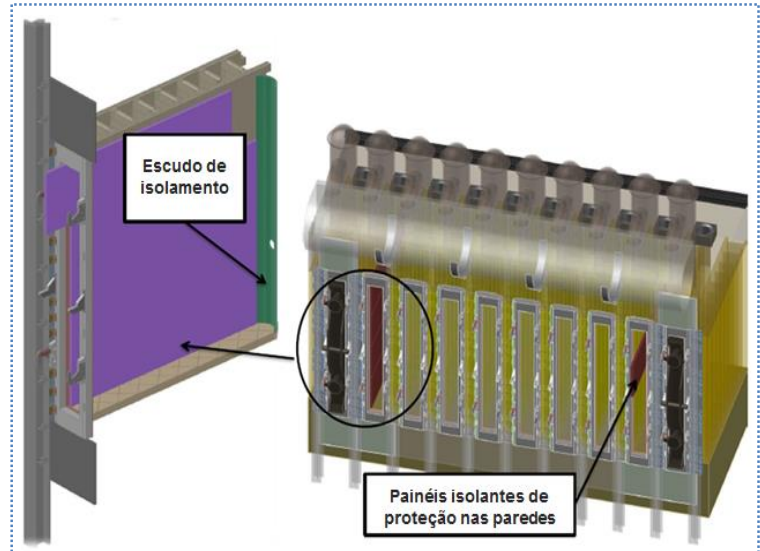

Figura 12 - Instalação de proteções e escudos

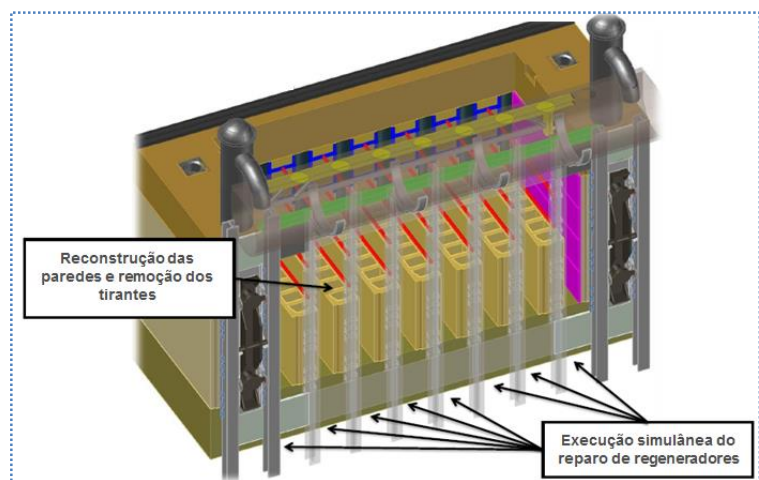

Figura 14 - Reconstrução das paredes
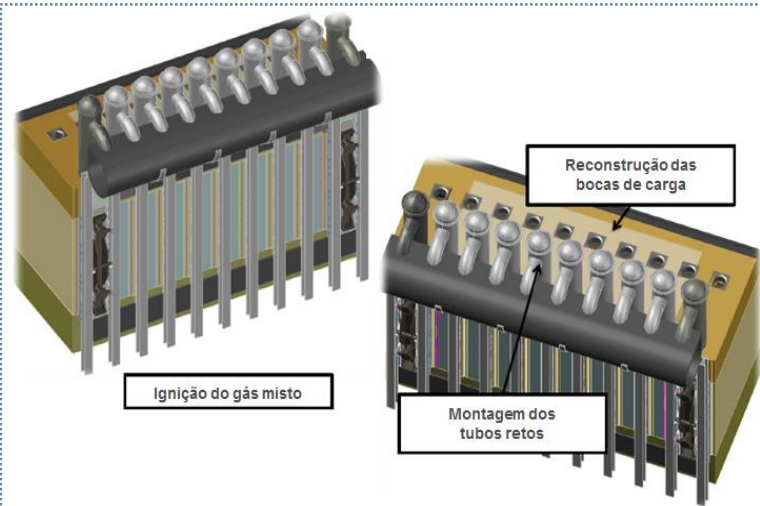

Figura 16 - Reconstrução do topo

\subsection{Tipos de reformas em Baterias de Coque}

\subsubsection{Reforma a quente com a bateria em operação}

Nesse tipo de reforma são paralisados alguns fornos para serem submetidos a reparo:

- Reparo em blocos de 1 a 10 paredes ou acima

- A bateria continua parcialmente em operação com os demais fornos

- Existe uma menor perda de produção com uma operação parcial;

- Ocorrência de interferência com operação. 


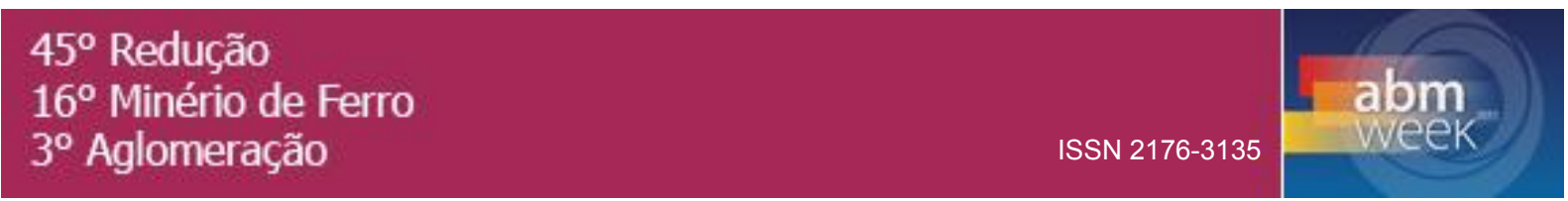

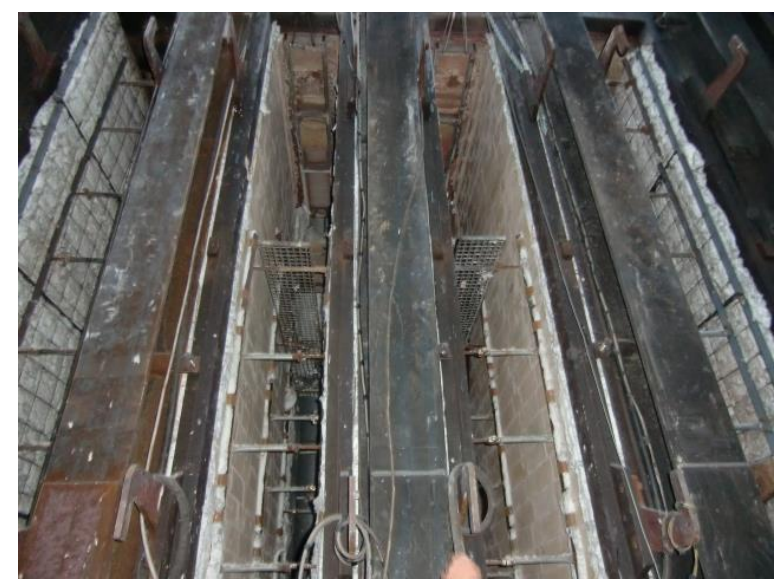

Figura 17 - Visão dos fornos em reforma

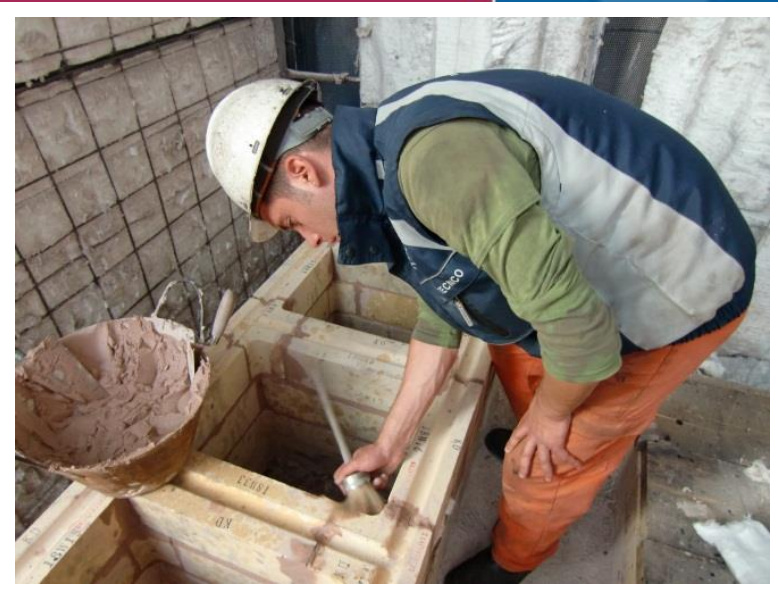

Figura 18 - Reconstrução das câmaras

\subsubsection{Reforma a quente com a bateria paralisada}

Nesse tipo de reforma a bateria é paralisada e blocos com maior número de fornos são submetidos a reparo simultaneamente. Em alguns casos pode-se executar a reforma parcial de todos os fornos ao mesmo tempo.

- Bateria paralisada total ou parcialmente.

- Reparo em blocos com maior número de fornos;

- Perda de produção equivalente aos fornos em reparo;

- Maior produtividade do reparo por não haver interferência com a operação.

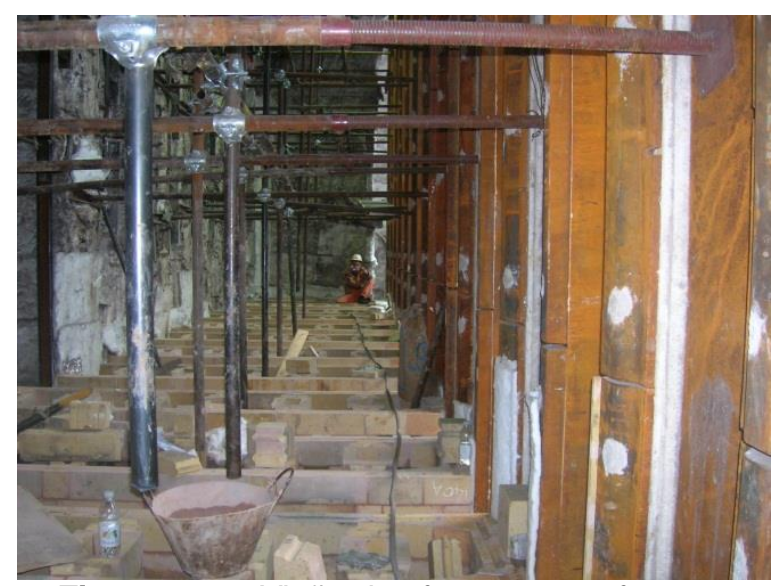

Figura 19 - Visão dos fornos em reforma

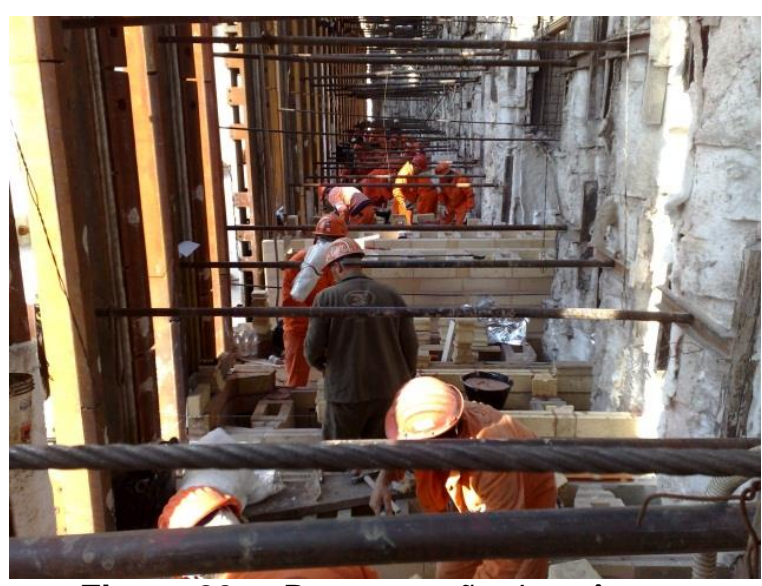

Figura 20 - Reconstrução das câmaras

\subsubsection{Reforma a frio das baterias}

Nesse tipo de reforma ocorre a completa demolição e reconstrução da parte refratária das baterias, até a laje de sustentação.

Todas as estruturas refratárias dos fornos são substituídas: topo, paredes, corbel, regeneradores, e demais áreas.

Esse tipo de reforma permite uma modernização no projeto dos fornos, preservando suas dimensões funcionais, porém com introdução de melhorias importantes. 


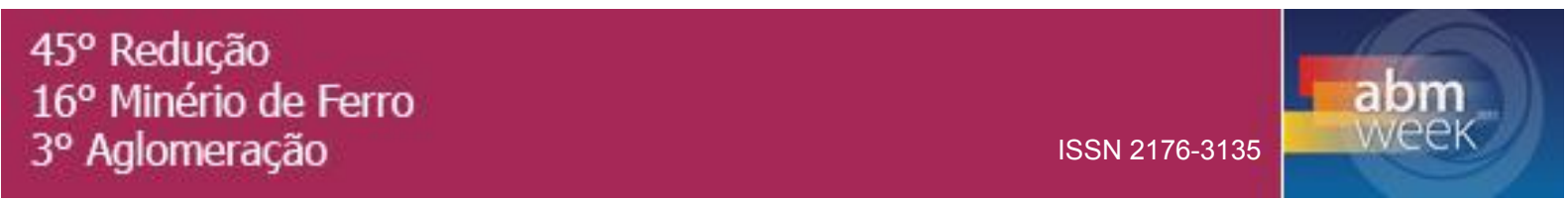

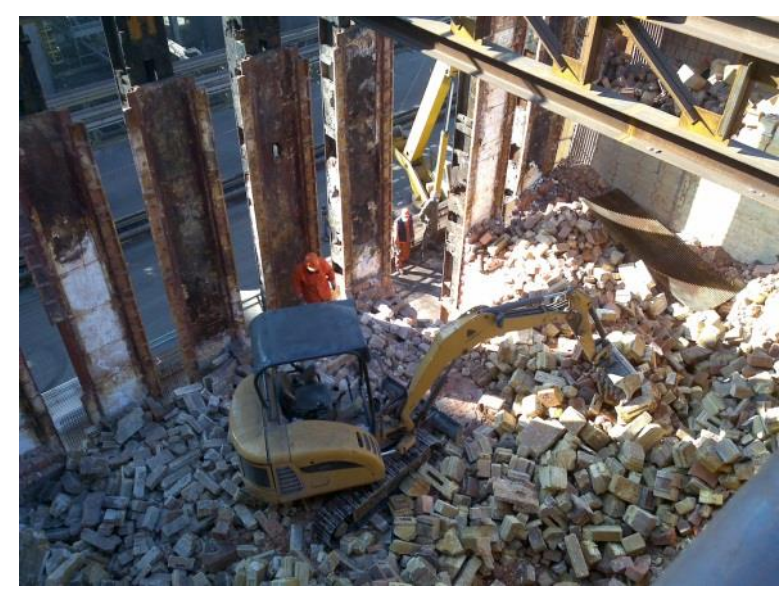

Figura 21 - Demolição completa da bateria

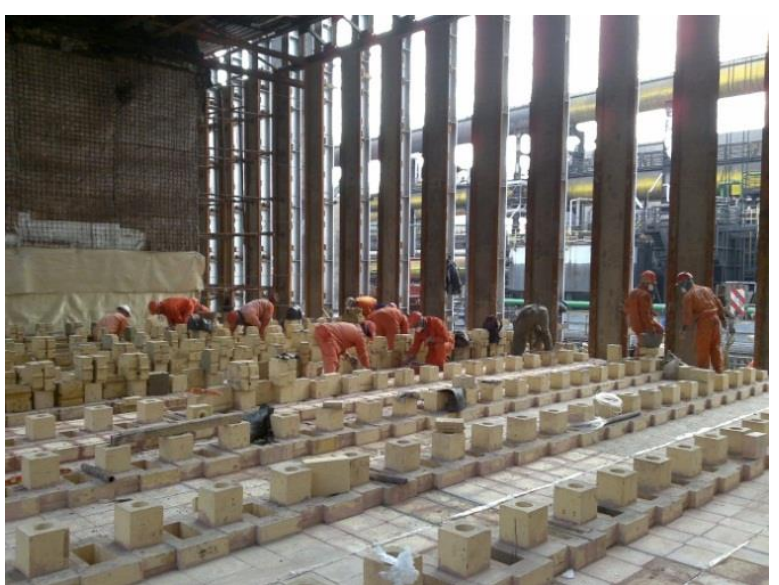

Figura 22 - Reconstrução das paredes

\section{CONCLUSÃO}

As baterias de coque são equipamentos essenciais à siderurgia integrada e apresentam uma extensa vida útil. A degradação natural e progressiva das suas estruturas deve ser permanentemente acompanhada em diagnoses periódicas e em cada fase da vida útil devem ser aplicados os métodos de operação, manutenção e preservação compatíveis à idade e desgaste das baterias.

O correto monitoramento das diagnoses indicará o momento adequado de se executar uma reforma de grande porte nas baterias. A postergação do momento ideal de realização da reforma poderá causar uma aceleração descontrolada das danificações, em progressão geométrica, levando não raro ao colapso e paralisação precoce da bateria, antecipando sua vida útil, com sérios prejuízos à empresa.

A reforma a quente de baterias de fornos de coque é uma tecnologia madura e aplicável, apresentando uma adequada relação custo benefício. O princípio que rege o conceito de reforma é o de preservar e reutilizar as estruturas das baterias ainda em boas condições e substituir apenas as partes danificadas sem condições de uso. A reforma garante uma significativa sobrevida às baterias, adiando o momento da desativação e postergando o investimento da construção de uma nova coqueria.

A Paul Wurth oferece atualmente ao mercado siderúrgico um completo rol de opções em termos de recuperação de baterias desde execução reformas a quente, reconstrução total e fornecimento baterias novas. Investimentos em tecnologia e capacitação permanente de sua equipe de colaboradores asseguram uma engenharia de reparo moderna e atualizada, com referencias comprovadas.

\section{REFERÊNCIAS}

1 Nippon Steel Corporation - Coke Oven Technology Technical articles and papers.

2 Costa, Luiz Cláudio (Usiminas Cosipa) - Tecnologia de Reformas e Reparos em Coquerias - artigos e informações técnicas.

3 Valdevies, Francesco - Coke Oven Repair Technology - technical information photos and sketch 